\title{
Risk factors for acute knee injury in female youth football.
}

\author{
Martin Hägglund and Markus Waldén
}

Linköping University Post Print

Tweet

N.B.: When citing this work, cite the original article.

The original publication is available at www.springerlink.com:

Martin Hägglund and Markus Waldén, Risk factors for acute knee injury in female youth football., 2016, Knee Surgery, Sports Traumatology, Arthroscopy, (24), 3, 737-746.

http://dx.doi.org/10.1007/s00167-015-3922-z

Copyright: Springer Verlag (Germany)

http://www.springerlink.com/?MUD=MP

Postprint available at: Linköping University Electronic Press

http://urn.kb.se/resolve?urn=urn:nbn:se:liu:diva-125909 


\section{Risk factors for acute knee injury in female youth football}

Martin Hägglund ${ }^{1,2}$ PT, PhD, Markus Waldén ${ }^{2-4}$ MD, PhD

${ }^{1}$ Linköping University, Department of Medical and Health Sciences, Division of

Physiotherapy, SE-58183 Linköping, Sweden.

${ }^{2}$ Football Research Group, Linköping, Sweden.

${ }^{3}$ Linköping University, Department of Medical and Health Sciences, Division of Community Medicine, SE-58183 Linköping, Sweden.

${ }^{4}$ Department of Orthopaedics, Hässleholm-Kristianstad-Ystad Hospitals, Hässleholm, Sweden.

\section{Corresponding author:}

Martin Hägglund

E-mail: martin.hagglund@liu.se

Tel: $+46-13281388$ 
2 Risk factors for acute knee injury in female youth football

3

4

5 


\section{ABSTRACT}

Purpose: To prospectively evaluate risk factors for acute time-loss knee injury, in particular ACL injury, in female youth football players.

Methods: Risk factors were studied in 4,556 players aged 12-17 years from a randomised controlled trial during the 2009 season. Covariates were both intrinsic (body mass index, age, relative age effect, onset of menarche, previous acute knee injury or ACL injury, current knee complaints, and familial disposition of ACL injury) and extrinsic (no. of training sessions/week, no. of matches/week, match exposure ratio, match play with other teams, and artificial turf exposure). Hazard ratios (HRs) and 95\% confidence intervals (CIs) were calculated from individual variable and multiple Cox regression analyses.

Results: 96 acute knee injuries were recorded, 21 of them ACL injuries. Multiple Cox regression showed a 4-fold higher ACL injury rate for players with familial disposition of ACL injury (HR 3.57; 95\% CI 1.48-8.62). Significant predictor variables for acute knee injury were age $>14$ years (HR 1.97; 95\% CI 1.30-2.97), knee complaints at the start of the season (HR 1.98; 95\% CI 1.30-3.02), and familial disposition of ACL injury (HR 1.96; 95\% CI 1.223.16). No differences in injury rates were seen when playing on artificial turf compared with natural grass.

Conclusions: Female youth football players with a familial disposition of ACL injury had an increased risk of ACL injury and acute knee injury. Older players and those with knee complaints at preseason were more at risk for acute knee injury. Although the predictive values were low, these factors could be used in athlete screening to target preventive interventions.

\section{Level of evidence: II}

Key words: ACL, epidemiology, female athlete, soccer, knee, prevention 


\section{INTRODUCTION}

Football is the world's most popular sport with more than 265 million players according to the Big Count of the Féderation International de Football Association (FIFA) in 2006.[11] The injury rate is low for girls younger than 12 years playing 5- or 7-a-side football, but approaches that of senior players in older (teenage) females participating in 11-a-side football.[8, 13] Acute knee injuries, especially anterior cruciate ligament (ACL) injuries, are of particular concern for the adolescent female athlete participating in cutting and pivoting sports.[31, 35, 43]

Given the high injury rate in adolescent and senior female football players, injury prevention is of upmost importance. In order to properly design a preventive intervention, knowledge about the risk factors associated with injury occurrence is needed. Risk factors are traditionally divided into intrinsic (player related) and extrinsic (environmental) factors.[3] The majority of studies identifying or discussing potential risk factors for knee injuries in female football players have almost exclusively focused on ACL injury. Based on the findings from these studies, there seems to be a consensus that: (i) female sex is associated with a higher ACL injury rate,[1, 2, 4, 14, 15, 43] (ii) the ACL injury rate increases for girls in their adolescence,[4, 32, 34, 43] and (iii) the ACL injury rate is higher during match play compared with training.[4, 9, 14, 15, 17, 27, 43] In addition, previous ACL injury has been associated with a several-fold increased ACL injury rate in female elite players,[10] and the ACL injury rates in male and female collegiate football players were lower on artificial turf compared with natural grass.[14, 15] Few risk factor studies to date have used multiple variable analyses. In addition, the influence of intrinsic risk factors such as anthropometrics, maturation status and relative age effect, as well as extrinsic risk factors such as match 
57 frequency and match play with older teams have not been well studied in football. The

58 objective of this study was therefore to evaluate risk factors for acute knee injury, in particular

59 ACL injury, in female youth football players using multiple analyses to account for the

60 influence of both intrinsic and extrinsic risk factors in tandem. 


\section{METHODS}

This was a sub-study of a previous cluster randomised controlled trial (RCT) that evaluated the preventive efficacy of a neuromuscular training program in female youth football. The overall study design and the results of the intervention have been published.[18, 19, 41] The main RCT showed a significant $64 \%$ reduction in the ACL injury rate in the intervention group compared with the control group.[41] In the present sub-study, risk factors for acute knee injury and ACL injury were investigated prospectively in the total study cohort (control and intervention group clubs). This approach was chosen to increase statistical power of the analyses, and as a result all analyses were adjusted for group belonging. Clubs were recruited from the female U-14 to U-18 series (age 12 to 17 years) in eight regional districts of the Swedish Football Association in 2009. The analysed sample included 230 clubs with 4,556 players; mean \pm SD age $14.1 \pm 1.2$ years, weight $53.3 \pm 8.6 \mathrm{~kg}$, height $163.6 \pm 6.7 \mathrm{~cm}$, and BMI $19.9 \pm 2.5 \mathrm{~kg} / \mathrm{m}^{2}$. There are 24 regional football districts in Sweden and the included sample is believed to be representative of the targeted age group.

\section{Study procedures and outcomes}

The data collection procedures and definitions used follow international guidelines for football injury surveillance.[16, 20] Sixty-eight study physiotherapists and 8 study physicians were recruited to serve as medical support to all clubs and assist the coaches with data registration. Data were collected during a full competitive playing season (April 1 through October 31, 2009). Injury surveillance included a baseline questionnaire with player variables (intrinsic risk factors), a player attendance form with exposure variables (extrinsic risk factors), and an injury report form. Each coach registered individual playing time (minutes of participation for each player) and absences (due to acute knee injury or other reasons) for each 
training session and match and sent the player attendance form by e-mail to the study physiotherapist and study centre each month. If a player had additional playing time with a district or national team, or another team within the club, this was also registered on the player attendance form. Playing surface was documented for each exposure, as natural grass, artificial turf or other (gravel, indoor). Acute knee injuries were reported by the coach as soon as possible after the event to the responsible study therapist who evaluated the injury in person and documented the injury. A recordable acute knee injury was one that occurred during organised football training or match play, had a sudden onset, and led to a player being unable to fully participate in future training or match play (excluding contusions).[19] Injury severity was defined according to the number of lay off days from injury to return to full training and availability for match play. Readiness to return to play was decided by the coach and player together with the healthcare professional responsible for treatment/rehabilitation. ACL injury was defined as a first-time or recurrent partial or total rupture of the ligament either isolated or associated with concomitant injuries to the knee joint.[42] Players with suspected ACL injury were routinely offered examination with magnetic resonance imaging (MRI). If any information was missing or was unclear, the player, coach or study physiotherapist was contacted for further clarification.

\section{Ethical approval}

The study was approved by the regional ethical review board in Linköping (Dnr M197-08). Players and guardians gave individual written informed consent.

\section{Statistical analysis}

The primary outcome was the ACL injury rate and the secondary outcome was any acute knee injury rate. Injury rates in match play vs. training, on artificial turf vs. natural grass, and 
between the players' own team vs. other teams, were compared with a rate ratio (RR) and 95\% confidence interval (CI), and $P$ value was calculated with z-statistics.[28] The influence

of playing surface on injury rates was evaluated for training and matches with the players' own team only. Comparison of injury distribution between the dominant and non-dominant leg was made with a one sample z-test for proportions, assuming an equal proportion of 0.5. Group comparisons (injured vs. uninjured players, players with vs. without exposure with other teams) were made with one-way analysis of variance (ANOVA) for continuous variables and the $\mathrm{Chi}^{2}$ test for categorical variables.

Risk factor analysis was performed using Cox regression analysis, and presented as a hazard ratio (HR) with 95\% CI, and $P$ value was calculated from the Wald's test. Covariates included in the risk factor analysis were both intrinsic and extrinsic. Intrinsic variables were: body mass index (BMI), age, relative age effect defined as being born in the first half of the calendar year (yes/no), onset of menarche (yes/no), previous acute knee injury or ACL injury, respectively (yes/no), current knee complaints at study start (yes/no), and familial disposition of ACL injury among parents or siblings (yes/no). Extrinsic variables were: number of training sessions per week, number of matches per week, match exposure ratio expressed as match hours/total hours of exposure, match play with other teams (yes/no), and exposure to artificial turf playing surface (yes/no). All continuous variables were dichotomised based on the cohort mean value (below or above mean) before being entered into the analyses. In the first step, individual variable Cox regression analyses were performed for all variables separately, while all analyses were adjusted for group belonging (control or intervention group) due to the previously identified preventive efficacy of the intervention.[18, 41] In the second step, variables with $P<0.20$ were then entered into a multiple Cox regression analysis, again adjusting for group belonging. We checked for interaction effects between 
136 group belonging and all covariates included in the multiple Cox regression analysis, and since

137 no significant interaction effects were present (all n.s.) no interaction terms were included in 138 the final models. The sensitivity, specificity, and positive and negative predictive values in 139 predicting new acute knee injury or ACL injury were calculated for variables that were 140 significant in the individual variable Cox regression analyses. All tests were 2-sided with a 141 significance level of $P<0.05$. Analyses were made using IBM SPSS Statistics for Windows 142 (Version 21.0. Armonk, NY: IBM Corp.) 


\section{Knee injury characteristics and exposure}

146

147

There were 96 acute knee injuries in 92 players (2.0\% of players) during 278,298 hours of football (203,662 training; 74,636 match play). The acute knee injury rate was 0.35/1000 hours, being several-fold higher in match play than in training (1.09 vs. 0.074/1000 hours, RR 14.74, 95\% CI 8.49-25.56, $P<0.001)$. Twenty-one players $(0.5 \%$ of players) suffered 21 ACL injuries, giving an injury rate of 0.076/1000 hours. The ACL injury rate was almost 9fold higher in match play compared with training ( 0.21 vs. $0.025 / 1000$ hours, RR $8.73,95 \%$ CI 3.20-23.86, $P<0.001)$. The characteristics of all acute knee injuries are presented in Table 1. As seen in Figure 1, the proportion of injured players tended to increase with higher age.

\section{Player's own team and other teams}

The majority of training (197,416 hours; 97\%) and match exposures (67,993 hours; 91\%) were registered with the players’ own team. There were 1194 players (26\%) who also had additional exposure with other teams, and they were older (14.3 \pm 1.2 vs $14.0 \pm 1.2$ years, $P<$ 0.001), played more matches $(0.91 \pm 0.31$ vs $0.65 \pm 0.27$ per week, $P<0.001)$ and trained more often $(1.41 \pm 0.48$ vs $1.25 \pm 0.45$ per week, $P<0.001)$ than players without additional exposure. Players with additional exposure incurred 11 injuries (all during matches; 2 ACL injuries) when playing with other teams, and 14 injuries (13 during matches; 3 ACL injuries) when playing with their own team. The acute match knee injury rate for these players was higher when playing with other teams compared with their own team (1.66 vs 0.61/1000 hours; RR 2.72, 95\% CI 1.22-6.07, $P=0.015)$.

\section{Playing surface and injury rates}


Training surfaces were natural grass (166,938 hours; 85\%), artificial turf (18,185 hours; 9\%) and other surfaces (12,292 hours; 6\%), and for matches natural grass (60,622 hours; 89\%), artificial turf (5,800 hours; 9\%) and other surfaces (1,571 hours; 2\%). No differences in acute knee injury rates were seen between artificial turf and natural grass in training (0.06 vs. 0.08/1000 hours, RR 0.66, 95\% CI 0.09-4.99, n.s.) or match play (1.03 vs. 1.22/1000 hours, RR 0.85, 95\% CI 0.37-1.95, n.s.). The overall ACL injury rate did not differ between surfaces (artificial turf 2; grass 19; both 0.08 ACL injuries/1000 hours, RR 1.00, 95\% CI 0.23-4.29, n.s.).

\section{Risk factors for acute knee injury}

Injury distribution in the dominant $(n=44)$ and non-dominant $(n=46)$ leg (6 injuries in ambidextrous players excluded from analysis) did not differ from an expected equal proportion (n.s.). More injured players reported onset of menarche, they were heavier and had a higher BMI than uninjured players (Table 2). Older age, having knee complaints at baseline, and familial disposition of ACL injury were significantly associated with an increased rate of acute knee injury in the multiple Cox regression analysis (Table 3).

\section{Risk factors for ACL injury}

ACL injuries were more common $(P=0.011)$ in the non-dominant $(n=11)$ compared with the dominant leg ( $\mathrm{n}=6)$; 4 ACL injuries in ambidextrous players were excluded from this analysis. ACL-injured players had a higher mean age, higher mean weight, higher mean BMI and more commonly reported ACL injury within the family than uninjured players (Table 2). Familial disposition was associated with an increased ACL injury rate in the multiple Cox regression analysis (Table 4). 
193 Sensitivity, specificity, positive and negative predictive values

194 The sensitivity of significant variables from the individual variable Cox regression analyses to 195 predict new acute knee injury or ACL injury was generally low, ranging 17-87\%, and the 196 specificity ranged 26-92\% (Table 5). The positive predictive values ranged 1-4\% and negative 197 predictive values were all $\geq 98 \%$.

198 
The main finding in this prospective study on risk factors for acute knee injury in female youth football players was that players with familial disposition of ACL injury had an almost 4-fold higher ACL injury rate. Furthermore, older players, those with knee complaints at the start of the season, and those with familial disposition of ACL injury had an increased rate of any acute knee injury in general. No differences in acute knee and ACL injury rates were seen when playing on artificial turf compared with natural grass. injury overall. Our prospective data thus tally with findings in previous case control studies reporting up to nine times higher prevalence of ACL tear among family members of ACL injury during follow-up.[5] genetic factors may contribute to an increased ACL injury risk[33] Although the present study, in line with previous work, suggest that heredity could be included as a non-modifiable 
risk factor to screen for in female youth athletes, it should be noted that familial disposition had low sensitivity as a predisposing factor to ACL injury. Thus, the practical relevance for screening in the youth female football population may be limited.

\section{Age and injury risk}

Older players (15 years or older) had an almost 2-fold increased rate of acute knee injury and a similar, but non-statistically significant, increased rate of ACL injury. A higher proportion of injured players (acute knee injury and ACL injury) also reported onset of menarche, although menstrual status was not significantly associated with injury in the regression models. Pubertal stage has previously been linked to sports injury risk, with increased risks observed in Tanner stages 4 and 5 compared with stages 1 and 2.[30] A decrease in neuromuscular control about the knee for female athletes with maturation has been suggested. For example, Hewett et al.[23] showed that late pubertal or post-pubertal female athletes (Tanner stages 4 and 5, mean age 15.5 years) had greater medial knee motion in a drop vertical jump test compared with early pubertal (Tanner stages 2 and 3, mean age 12.6 years) and pre-pubertal (Tanner stage 1, mean age 11.5 years) females. Further, girls demonstrate poorer neuromuscular adaptations to the musculoskeletal changes that accompany maturation than boys,[23] possibly explaining the observed increased rate of acute knee ligament injury in late pubertal and postpubertal females. Similarly, post-menarche female artistic elite gymnasts (mean age 19.1 years), as compared with pre-menarche athletes (mean age 11.6 years), display greater maximum knee abduction angle and knee abduction moment during a one-legged drop jump test.[25] Greater knee abduction angles and moments have previously also been found to associate with future ACL injury risk.[24]

\section{Leg dominance and injury risk}


A higher prevalence of ACL injury was observed in the non-dominant (supporting) leg, which is similar to findings in a previous retrospective study on female footballers (mean age at injury 20.4 years) where $68 \%$ of non-contact ACL injuries occurred to the non-dominant leg.[6] It has been hypothesised that female athletes may be more limb dominant than males, showing, for example, a higher prevalence of side-to-side imbalances in muscular strength and joint kinematics.[31] One might thus speculate that differences in neuromuscular control between limbs, or a greater exposure to high-risk one-legged loading patterns on the nondominant limb (e.g. during shooting or passing, or during cutting manoeuvres) can contribute to an increased injury risk.

\section{Previous injury and current complaints}

In female elite players, previous ACL injury has been associated with a 5-fold increased ACL injury rate.[10] Only $0.9 \%$ of our study sample reported a previous ACL injury at baseline, and none in the subsequently ACL-injured group, and it was therefore not possible to conclude on previous ACL injury as a risk factor in this study. However, a higher proportion of players with previous acute knee injury, as well as current knee complaints, at baseline was observed in players who sustained an acute knee injury during the season. Previous knee injury and lower knee-related function and presence of symptoms at study start, based on the Knee injury and Osteoarthritis Outcome Score (KOOS), have previously also been reported to predict new knee injury in female adolescent football players.[7, 39] However, in line with the latter study,[39] the sensitivity in predicting future acute knee injury was low (17\%) and with a positive predictive value of only $4 \%$.

\section{Extrinsic factors and injury risk}


The ACL injury rate was almost 9-fold higher, and the overall acute knee injury rate 15-fold higher, in match play compared with training. This is in line with previous studies,[4, 9, 14, $15,17,27,43$ ] and shows the higher risk involved in football match play. Noteworthy is that ACL injury was a rare occurrence in our population of female youth football players, affecting less than $0.5 \%$ of all players in a season, with $0.28 \%$ and $0.67 \%$ in the intervention and control groups, respectively.[41] Our findings are similar to those previously reported from Norwegian female youth football (mean age 15.4 years) where 11 of 2020 players (0.5\%) suffered an ACL tear during a season,[38] and where 10 of 11 ACL injuries occurred in matches. This suggests that ACL injuries are not an epidemic in youth female football, and that football training is a fairly low risk activity from a knee injury perspective. The season incidence of ACL injury in senior female elite football is considerably higher (3-6\%),[43] indicating that the risk increases with higher age and higher levels of play.

Exposure to artificial turf playing surface was not a risk factor for acute knee injury or ACL injury in the present study. A previous study on youth female football players showed no overall difference in injury rates between artificial turf and grass, while the injury subtypes knee injuries and ligament injuries were more common on artificial turf.[38] The incidence of ACL injury, however, was not statistically significant between surfaces, although limited by a very small sample (three on grass, four on artificial turf). Another study from boys' and girls’ adolescent football showed no difference in knee injury rates between artificial turf and grass.[36] Other studies from male and female collegiate football players found that the ACL injury rates were lower on artificial turf compared with natural grass,[14, 15] or similar between surfaces.[29] Although the present study, and most other previous studies, suggest that artificial turf is a safe (equal to natural grass) football playing surface from a knee 
ligament injury perspective, more information on the influence of playing surface, weather conditions and the shoe-surface interaction and knee injury risk is warranted.

Finally, it has been a concern that young talented female players who play additional matches with other teams than their own team, e.g. with the senior team of the club[35] or with national teams, are more prone to suffer an acute knee injury. One-fourth of players in the present study had other team exposures and they were older and played more matches than those who only played with their own team. They also had an increased match injury rate when playing with other teams than their own team. However, the proportion of injured players was not different between those who played with other teams and those who did not, and exposure to match play with other teams was not associated with acute knee injury or ACL injury in the risk factor models. Moreover, no association between the weekly load of training sessions and matches, or the ratio of match play and training exposure, and knee injury risk was found in this study. A recent Danish study showed that neither the level of play nor the match/total exposure ratio were associated with the risk of any time-loss injury in adolescent female football players, and that a high weekly average exposure was associated with a lower injury risk.[8] In contrast, Soligard et al.[37] reported that high-skilled players had an overall higher injury rate than low-skilled players, and the authors speculated that these players are more highly involved in matches, and more prone to tackles and foul play, which could increase injury risk. However, no details on exposures with other teams were presented in that study, and direct comparison with our findings is therefore difficult. Clearly, more research on the influence of training and match load, including exposures with older youth teams and senior teams, and injury risk is needed before solid recommendations can be made. In the meantime, it seems reasonable to limit the exposure to match play with older 
youth teams and senior teams for young girls playing football, given the higher injury rate observed during these additional exposures.

\section{Study strengths and limitations}

Some strengths of the present study include the large sample involving more than 4,500 participants and individual playing time registration with no missing data for analysed clubs. Additionally, the medical support supplied through the study enabled quick and qualified examination of injuries by experienced sports medicine practitioners including a liberal policy for MRI referral, and it is therefore unlikely that any ACL injuries have been overseen.

This study also has some limitations. Low seasonal ACL injury and acute knee injury rates meant that some analyses suffer from a lack of power. As a rule of thumb, 10 outcome events per predictor variable (EPV) is often recommended for Cox regression, although it has also been suggested that models with 5-9 EPV could be sufficient.[40] In the multiple Cox regression models, we had 3.5 EPV for ACL injury, and 11.5 EPV for acute knee injury, and the results from the ACL injury risk factor model should be interpreted with some caution. To increase statistical power in this study, and like procedures used in previous similar studies,[37-39] we included also the intervention group teams/players from the original RCT.[41] As a result, all risk factor analyses were adjusted for group belonging, and we also checked for interaction between group belonging and all predictor variables included in the multiple models (all were n.s.). Even so, it is likely that the neuromuscular training intervention has influenced other potential risk factors not included in the present study, such as neuromuscular control, and these factors may also correlate with our measured risk factor variables. As previously discussed, neuromuscular control about the knee varies with maturation status in female athletes,[23, 25] and is related to knee injury risk,[24] and thus, a 
sufficiently sized prospective study in a sample of athletes receiving no intervention would have been optimal.

\section{CONCLUSION}

This prospective study on female youth football players showed that familial disposition of ACL injury, older age (15 years or older), and having knee complaints at the start of the season were factors that predisposed to an increased acute knee injury risk. Although the predictive values were low, these factors could be used in athlete screening to target preventive interventions.

\section{ACKNOWLEDGEMENTS}

We thank all the coaches and players who participated in the study as well as the study therapists and study physicians constituting the medical support to the teams. Professor Per

Swedish Football Association (FA) are gratefully acknowledged for study assistance. Isam

for their contribution to the original RCT. The study was financially supported by the Swedish FA and the Folksam Insurance Company. This research also received grants from the Swedish National Centre for Research in Sports and the Hässleholm Hospital.

\section{CONFLICT OF INTEREST}

The authors declare they have no conflict of interest. 


\section{REFERENCES}

371 1. Arendt EA, Agel J, Dick R (1999) Anterior cruciate ligament injury patterns among collegiate men and women. J Athl Train 34:86-92

2. Arendt EA, Dick R (1995) Knee injury patterns among men and women in collegiate basketball and soccer. NCAA data and review of literature. Am J Sports Med 23:694-701

3. Bahr R, Holme I (2003) Risk factors for sports injuries - a methodological approach. Br J Sports Med 37:384-392

4. Bjordal JM, Arnøy F, Hannestad B, Strand T (1997) Epidemiology of anterior cruciate ligament injuries in soccer. Am J Sports Med 25:341-345

5. Bourke HE, Salmon LJ, Waller A, Patterson V, Pinczewski LA (2012) Survival of the anterior cruciate ligament graft and the contralateral ACL at a minimum of 15 years. Am J Sports Med 40:1985-92

382

6. Brophy R, Silvers HJ, Gonzales T, Mandelbaum BR (2010) Gender influences: the role of

7. Clausen MB, Tang L, Zebis MK, Krustrup P, Hölmich P, Wedderkopp N, Andersen LL, Christensen KB, Møller M, Thorborg K (2015) Self-reported previous knee injury and low knee function increase knee injury risk in adolescent female football. Scand J Med Sci Sports. Doi: 10.1111/sms.12521

8. Clausen MB, Zebis MK, Møller M, Krustrup P, Hölmich P, Wedderkopp N, Andersen LL, Christensen KB, Thorborg K (2014) High injury incidence in adolescent female soccer. Am J Sports Med 42:2487-2494

9. Faude O, Junge A, Kindermann W, Dvorak J (2005) Injuries in female soccer players: a prospective study in the German national league. Am J Sports Med 33:1694-1700

10. Faude O, Junge A, Kindermann W, Dvorak J (2006) Risk factors for injuries in elite female soccer players. Br J Sports Med 40:785-790 
395 11. Fédération Internationale de Football Association. FIFA Big Count 2006: 270 million 396 people active in football. Available via www.fifa.com/worldfootball/bigcount/ Accessed 4 $397 \quad$ June 2015

398

12. Flynn RK, Pedersen CL, Birmingham TB, Kirkley A, Jackowski D, Fowler PJ (2005) The familial predisposition toward tearing the anterior cruciate ligament: a case control study. Am J Sports Med 33:23-28

13. Froholdt A, Olsen OE, Bahr R (2009) Low risk of injuries among children playing organized soccer. A prospective cohort study. Am J Sports Med 37:1155-1160

14. Fuller CW, Dick RW, Corlette J, Schmalz R (2007) Comparison of the incidence, nature and cause of injuries sustained on grass and new generation artificial turf by male and female football players. Part 1: match injuries. Br J Sports Med 41(Suppl 1):i20-i26

15. Fuller CW, Dick RW, Corlette J, Schmalz R (2007) Comparison of the incidence, nature and cause of injuries sustained on grass and new generation artificial turf by male and female football players. Part 2: training injuries. Br J Sports Med 41(Suppl 1):i27-i32

16. Fuller CW, Ekstrand J, Junge A, Andersen TE, Bahr R, Dvorak J, Hägglund M, McCrory P, Meeuwisse WH (2006) Consensus statement on injury definitions and data collection procedures in studies of football (soccer) injuries. Br J Sports Med 40:193-201

17. Giza E, Mithöfer K, Farrell L, Zarins B, Gill T (2005) Injuries in women’s professional soccer. Br J Sports Med 39:212-216

18. Hägglund M, Atroshi I, Wagner P, Waldén M (2013) Superior compliance with a neuromuscular training programme is associated with fewer ACL injuries and fewer acute knee injuries in female adolescent football players: secondary analysis of an RCT. Br J Sports Med 47:974-979 
19. Hägglund M, Waldén M, Atroshi I (2009) Preventing knee injuries in adolescent female football players - design of a cluster randomized controlled trial [NCT00894595]. BMC Musculoskeletal Disorders 23:75

20. Hägglund M, Waldén M, Bahr R, Ekstrand J (2005) Methods for epidemiological study of injuries to professional football players - developing the UEFA model. Br J Sports Med 39:340-346

21. Harner CD, Paulos LE, Greenwald AE, Rosenberg TD, Cooley VC (1994) Detailed analysis of patients with bilateral anterior cruciate ligament injuries. Am J Sports Med 22:37-43

22. Hewett TE, Lynch TR, Myer GD, Ford KR, Gwin RC, Heidt RS Jr (2010) Multiple risk factors related to familial predisposition to anterior cruciate ligament injury: fraternal twin sisters with anterior cruciate ligament ruptures. Br J Sports Med 44:848-855

23. Hewett TE, Myer GD, Ford KR (2004) Decrease in neuromuscular control about the knee with maturation in female athletes. J Bone Joint Surg 86:1601-1608

24. Hewett TE, Myer GD, Ford KR, Heidt RS Jr, Colosimo AJ, McLean SG, van den Bogert AJ, Paterno MV, Succop P (2005) Biomechanical measures of neuromuscular control and valgus loading of the knee predict anterior cruciate ligament injury risk in female athletes: a prospective study. Am J Sports Med 33:492-501

25. Kim KW, Lim BO (2014) Effects of menarcheal age on the anterior cruciate ligament injury risk factors during single-legged drop landing in female artistic elite gymnasts. Arch Orthop Trauma Surg 134:1565-1571

26. Lambert KL (1984) The syndrome of the torn anterior cruciate ligament. Adv Orthop Surg 7:304-314

27. Le Gall F, Carling C, Reilly T (2008) Injuries in young elite female soccer players. An 8season prospective study. Am J Sports Med 36:276-284 
28. Lindenfeld TN, Schmitt DJ, Hendy MP, Mangine RE, Noyes FR (1994) Incidence of injury in indoor soccer. Am J Sports Med 22:364-371

29. Meyers MC (2013) Incidence, mechanisms, and severity of match-related collegiate women's soccer injuries on FieldTurf and natural grass surfaces: a 5-year prospective study. Am J Sports Med 41:2409-2420

30. Michaud PA, Renaud A, Narring F (2001) Sports activities related to injuries? A survey among 9-19 years olds in Switzerland. Inj Prev 7:41-45

31. Myer GD, Ford KR, Hewett TE (2004) Rationale and clinical techniques for anterior cruciate ligament injury prevention among female athletes. J Athl Train 39:352-364

32. Roos H, Ornell M, Gärdsell P, Lohmander LS, Lindstrand A (1995) Soccer after anterior cruciate ligament injury - an incompatible combination? A national survey of incidence and risk factors and a 7-year follow-up of 310 players. Acta Orthop Scand 66:107-112

33. September AV, Posthumus M, Collins M (2012) Application of genomics in the prevention, treatment and management of Achilles tendinopathy and anterior cruciate ligament ruptures. Recent Pat DNA Gene Seq 6:216-223

34. Shea KG, Pfeiffer R, Wang JH, Curtin M, Apel PJ (2004) Anterior cruciate ligament injury in pediatric and adolescent soccer players: an analysis of insurance data. J Pediatr Orthop 24:623-628

35. Söderman K, Pietilä T, Alfredson H, Werner S (2002) Anterior cruciate ligament injuries in young females playing soccer at senior levels. Scand J Med Sci Sports 12:65-68

36. Soligard T, Bahr R, Andersen TE (2012) Injury risk on artificial turf and grass in youth tournament football. Scand J Med Sci Sports 22:356-361

37. Soligard T, Grindem H, Bahr R, Andersen TE (2010) Are skilled players at greater risk of injury in female youth football? Br J Sports Med 44:1118-1123 
467 38. Steffen K, Andersen TE, Bahr R (2007) Risk of injury on artificial turf and natural grass in young female football players. Br J Sports Med 41(Suppl 1):i33-i37

469

470

471

472

473

474

475

476

477

478

479

480

481

482

483

484

485

39. Steffen K, Myklebust G, Andersen TE, Holme I, Bahr R (2008) Self-reported injury history and lower limb function as risk factors for injuries in female youth soccer. Am $\mathrm{J}$ Sports Med 36:700-708

40. Vittinghoff E, McCulloch CE (2007) Relaxing the rule of ten events per variable in logistic and Cox regression. Am J Epidemiol 165:710-718

41. Waldén M, Atroshi I, Magnusson H, Wagner P, Hägglund M (2012) Prevention of acute knee injuries in adolescent female football players: cluster randomised controlled trial. BMJ 344:e3042 Doi: 10.1136/bmj.e3042

42. Waldén M, Hägglund M, Magnusson H, Ekstrand J (2011) Anterior cruciate ligament injury in elite football: a prospective three-cohort study. Knee Surg Sports Traumatol Arthrosc 19:11-19

43. Waldén M, Hägglund M, Werner J, Ekstrand J (2011) The epidemiology of anterior cruciate ligament injury in football (soccer): a review of the literature from a genderrelated perspective. Knee Surg Sports Traumatol Arthrosc 19:3-10 
TABLE 1 Acute knee injury characteristics in female youth football players

Footnotes

ACL, anterior cruciate ligament.

${ }^{a}$ Reported diagnoses (multiple diagnoses per injury event possible) of knee injuries were medial collateral ligament sprain ( $n=28)$, capsular sprain $(n=26)$, ACL tear $(n=21)$, patella dislocation/subluxation $(n=13)$, meniscus tear $(n=12)$, lateral collateral ligament sprain $(n=8)$, cartilage lesion $(n=4)$ and fracture $(n=2)$.

${ }^{\mathrm{b}}$ As reported at up to 1 year follow-up after injury.

TABLE 2 Baseline characteristics and exposure data for uninjured players, and players sustaining acute knee injury or ACL Injury

Footnotes

ACL, anterior cruciate ligament; BMI, body mass index.

a P value from significance testing with ANOVA (continuous variables) or the Chi2 test (categorical variables).

b Exposure data are reported up to first injury event (injured players) or during entire season (uninjured players). c Match hours/total hours of exposure.

d Number of players who played matches with a district or national team or older youth/senior team within the club during study inclusion.

TABLE 3 Risk factors for acute knee injury based on Cox regression analysis

Footnotes

BMI, body mass index; CI, confidence interval.

a All analyses adjusted for group belonging (intervention or control group)

b Variable dichotomised according to below or above cohort mean.

c Match hours/total hours of exposure. 
d Variables with $\mathrm{P}<0.20$ in individual variable analysis were entered into multiple analysis.

TABLE 4 Risk factors for ACL injury based on Cox regression analysis

Footnotes

ACL, anterior cruciate ligament; BMI, body mass index; CI, confidence interval.

a All analyses adjusted for group belonging (intervention or control group).

b Variable dichotomised according to below or above cohort mean.

c Match hours/total hours of exposure.

d Variables with $\mathrm{P}<0.20$ in individual variable analysis were entered into multiple analysis.

TABLE 5 Sensitivity, specificity, positive and negative predictive values of variables to predict new acute knee injury or ACL injury.

Footnotes

ACL, Anterior cruciate ligament; BMI, Body mass index; PPV Positive predictive value; NPV Negative predictive value

FIGURE 1 Injury proportions by age group 
TABLE 1

Acute knee injury characteristics in female youth football players

\begin{tabular}{|c|c|c|}
\hline & Acute Knee Injuries $(n=96)$ & ACL Injuries $(n=21)$ \\
\hline \multicolumn{3}{|l|}{ Activity } \\
\hline Training & $15(16 \%)$ & $5(24 \%)$ \\
\hline Match play & $81(84 \%)$ & $16(76 \%)$ \\
\hline \multicolumn{3}{|l|}{ Injury mechanism } \\
\hline Contact & $53(55 \%)$ & $8(38 \%)$ \\
\hline Noncontact & $43(45 \%)$ & $13(62 \%)$ \\
\hline \multicolumn{3}{|l|}{ Leg dominance } \\
\hline Dominant leg & $44(46 \%)$ & $6(29 \%)$ \\
\hline Nondominant leg & $46(48 \%)$ & $11(52 \%)$ \\
\hline Player ambidextrous & $6(6 \%)$ & $4(19 \%)$ \\
\hline \multicolumn{3}{|l|}{ Severity } \\
\hline 1-7 days absence & $10(10 \%)$ & - \\
\hline 8-28 days absence & $29(30 \%)$ & - \\
\hline$>28$ days absence & 57 (59\%) & $21(100 \%)$ \\
\hline \multicolumn{3}{|l|}{ Surface } \\
\hline Grass & $88(92 \%)$ & 19 (91\%) \\
\hline Artificial turf & $7(7 \%)$ & $2(10 \%)$ \\
\hline Other & $1(1 \%)$ & - \\
\hline \multicolumn{3}{|l|}{ Recurrence } \\
\hline Yes & $8(8 \%)$ & - \\
\hline \multicolumn{3}{|l|}{ Injury situation } \\
\hline Playing with own team & 85 (89\%) & 19 (91\%) \\
\hline Playing with older youth team & $5(5 \%)$ & $1(5 \%)$ \\
\hline Playing with senior team & $6(6 \%)$ & $1(5 \%)$ \\
\hline \multicolumn{3}{|l|}{ Diagnostics $^{\mathrm{a}}$} \\
\hline Radiograph & 33 (34\%) & $13(62 \%)$ \\
\hline MRI & 34 (35\%) & 17 (81\%) \\
\hline Arthroscopy & 11 (11\%) & $6(29 \%)$ \\
\hline \multicolumn{3}{|l|}{ Treatment $^{\mathrm{b}}$} \\
\hline Nonsurgical & 79 (82\%) & $8(38 \%)$ \\
\hline Surgical & 17 (18\%) & $13(62 \%)$ \\
\hline
\end{tabular}

ACL, anterior cruciate ligament.

${ }^{a}$ Reported diagnoses (multiple diagnoses per injury event possible) of knee injuries were medial collateral ligament sprain ( $n=28)$, capsular sprain $(n=26)$, ACL tear $(n=21)$, patella dislocation/subluxation $(n=13)$, meniscus tear $(n=12)$, lateral collateral ligament sprain $(n=8)$, cartilage lesion $(n=4)$ and fracture $(n=2)$.

${ }^{\mathrm{b}}$ As reported at up to 1 year follow-up after injury. 
TABLE 2

Baseline characteristics and exposure data for uninjured players, and players sustaining acute knee injury or ACL injury

\begin{tabular}{|c|c|c|c|c|c|c|}
\hline \multirow[b]{2}{*}{ Variable } & \multicolumn{3}{|c|}{ Acute knee injury } & \multicolumn{3}{|c|}{ ACL injury } \\
\hline & No $(n=4472)$ & Yes $(n=92)$ & $P$ value $^{\mathrm{a}}$ & No $(n=4543)$ & Yes $(n=21)$ & $P$ value ${ }^{\mathrm{a}}$ \\
\hline Mean (SD) age (years) & $14.1(1.2)$ & $14.5(1.3)$ & 0.001 & $14.1(1.2)$ & $15.0(0.9)$ & 0.001 \\
\hline \multicolumn{7}{|l|}{ Age distribution (years) } \\
\hline 12 & $272(6 \%)$ & $3(3 \%)$ & & $275(6 \%)$ & 0 & \\
\hline 13 & $1413(32 \%)$ & $20(22 \%)$ & & $1432(32 \%)$ & $1(5 \%)$ & \\
\hline 14 & 1312 (29\%) & $23(25 \%)$ & & $1330(29 \%)$ & $5(24 \%)$ & \\
\hline 15 & $868(19 \%)$ & 27 (29\%) & & 885 (19\%) & $10(48 \%)$ & \\
\hline 16 & $424(9 \%)$ & $11(12 \%)$ & & $431(9 \%)$ & $4(19 \%)$ & \\
\hline 17 & $183(4 \%)$ & $8(9 \%)$ & & $190(4 \%)$ & $1(5 \%)$ & \\
\hline Born first half of year, yes & $1741 / 4472$ (39\%) & 40/92 (43\%) & n.s. & $1768 / 4543(39 \%)$ & $13 / 21(62 \%)$ & 0.031 \\
\hline Mean (SD) height (cm) & $163.6(6.7)$ & $164.6(6.2)$ & n.s. & $163.6(6.7)$ & $165.9(5.8)$ & n.s. \\
\hline Mean (SD) weight (kg) & $53.3(8.5)$ & $55.2(7.9)$ & 0.036 & $53.3(8.5)$ & $58.2(8.5)$ & 0.011 \\
\hline Mean (SD) BMI $\left(\mathrm{kg} / \mathrm{m}^{2}\right)$ & $19.9(2.5)$ & $20.4(2.3)$ & n.s. & $19.9(2.5)$ & $21.1(2.3)$ & 0.027 \\
\hline Menarche, yes & $3123 / 4199$ (74\%) & 77/89 (87\%) & 0.009 & $3180 / 4267(75 \%)$ & 20/21 (95\%) & 0.030 \\
\hline Previous ACL injury, yes & $38 / 4316(0.9 \%)$ & 1/92 (1.1\%) & n.s. & 39/4387 (0.9\%) & $0 / 21$ & n.s. \\
\hline Current knee complaints, yes & $1052 / 4315(24 \%)$ & 35/92 (38\%) & 0.003 & $1082 / 4386(25 \%)$ & $5 / 21(24 \%)$ & n.s. \\
\hline Familial disposition ACL injury, yes & $633 / 4211(15 \%)$ & $23 / 90(26 \%)$ & 0.006 & $648 / 4280(15 \%)$ & $8 / 21(38 \%)$ & 0.004 \\
\hline \multicolumn{7}{|l|}{ Exposure $^{\mathrm{b}}$} \\
\hline Mean (SD) no of training sessions per week & $1.30(0.46)$ & $1.40(0.56)$ & 0.033 & $1.29(0.46)$ & $1.40(0.63)$ & n.s. \\
\hline Mean (SD) no of matches per week & $0.72(0.30)$ & $0.78(0.38)$ & n.s. & $0.72(0.30)$ & $0.84(0.48)$ & n.s. \\
\hline Mean (SD) match exposure ratio ${ }^{c}$ & $0.26(0.10)$ & $0.28(0.17)$ & n.s. & $0.26(0.10)$ & $0.28(0.21)$ & n.s. \\
\hline Match with other team, yes ${ }^{\mathrm{d}}$ & $1169 / 4472(26 \%)$ & 24/92 (26\%) & n.s. & $1189 / 4543(26 \%)$ & $5 / 21(24 \%)$ & n.s. \\
\hline Artificial turf exposure, yes & $2441 / 4472(55 \%)$ & 47/92 (51\%) & n.s. & $2476 / 4543(55 \%)$ & $12 / 21(57 \%)$ & n.s. \\
\hline
\end{tabular}

ACL, anterior cruciate ligament; BMI, body mass index.

a $P$ value from significance testing with ANOVA (continuous variables) or the $\mathrm{Chi}^{2}$ test (categorical variables).

${ }^{\mathrm{b}}$ Exposure data are reported up to first injury event (injured players) or during entire season (uninjured players).

c Match hours/total hours of exposure.

${ }^{\mathrm{d}}$ Number of players who played matches with a district or national team or older youth/senior team within the club during study inclusion. 
TABLE 3

Risk factors for acute knee injury based on Cox regression analysis

\begin{tabular}{|c|c|c|c|c|}
\hline Analysis & Variable & $\begin{array}{l}\text { Hazard } \\
\text { Ratio }\end{array}$ & Ratio & $P$ value \\
\hline \multicolumn{5}{|c|}{ Step 1. Individual variable analysis ${ }^{\mathrm{a}}$} \\
\hline \multirow[t]{7}{*}{ Intrinsic factors } & Age $>14$ years $^{\mathrm{b}}$ & 1.97 & $1.30-2.97$ & 0.001 \\
\hline & Born first half of year, yes & 1.21 & $0.80-1.83$ & n.s. \\
\hline & $\mathrm{BMI}>19.9 \mathrm{~kg} / \mathrm{m}^{2 \mathrm{~b}}$ & 1.53 & $1.00-2.32$ & 0.048 \\
\hline & Menarche, yes & 2.19 & $1.19-4.02$ & 0.012 \\
\hline & Previous acute knee injury, yes & 2.47 & $1.44-4.23$ & 0.001 \\
\hline & Current knee complaints, yes & 1.98 & 1.30-3.02 & 0.001 \\
\hline & Familial disposition ACL injury, yes & 1.96 & $1.22-3.16$ & 0.005 \\
\hline \multirow[t]{5}{*}{ Extrinsic factors } & Training sessions per week $>1.30^{\mathrm{b}}$ & 0.92 & $0.60-1.42$ & n.s. \\
\hline & Matches per week $>0.72^{b}$ & 0.90 & $0.59-1.38$ & n.s. \\
\hline & Match exposure ratio $>0.26^{\mathrm{b}, \mathrm{c}}$ & 0.93 & $0.61-1.39$ & n.s. \\
\hline & Match with other team, yes & 0.74 & $0.46-1.19$ & n.s. \\
\hline & Artificial turf exposure, yes & 0.74 & $0.49-1.12$ & 0.150 \\
\hline \multicolumn{5}{|c|}{ Step 2. Multiple analysis ${ }^{\mathrm{a}, \mathrm{d}}$} \\
\hline & Age $>14$ years $^{b}$ & 1.82 & $1.13-2.92$ & 0.014 \\
\hline & $\mathrm{BMI}>19.9 \mathrm{~kg} / \mathrm{m}^{2 \mathrm{~b}}$ & 1.26 & $0.80-1.97$ & n.s. \\
\hline & Menarche, yes & 1.42 & $0.73-2.79$ & n.s. \\
\hline & Previous acute knee injury, yes & 1.68 & $0.94-3.00$ & n.s. \\
\hline & Current knee complaints, yes & 2.06 & $1.30-3.26$ & 0.002 \\
\hline & Familial disposition ACL injury, yes & 1.87 & $1.15-3.03$ & 0.012 \\
\hline & Artificial turf exposure, yes & 0.69 & $0.44-1.06$ & n.s. \\
\hline
\end{tabular}

BMI, body mass index; CI, confidence interval.

${ }^{a}$ All analyses adjusted for group belonging (intervention or control group)

${ }^{\mathrm{b}}$ Variable dichotomised according to below or above cohort mean.

${ }^{\mathrm{c}}$ Match hours/total hours of exposure.

${ }^{\mathrm{d}}$ Variables with $P<0.20$ in individual variable analysis were entered into multiple analysis. 
TABLE 4

Risk factors for ACL injury based on Cox regression analysis

\begin{tabular}{|c|c|c|c|c|}
\hline \multirow[t]{2}{*}{ Analysis } & \multirow[t]{2}{*}{ Variable } & Hazard & $95 \%$ CI & $P$ value \\
\hline & & \multicolumn{3}{|l|}{ Ratio } \\
\hline \multicolumn{5}{|c|}{ Step 1. Individual variable analysis ${ }^{\mathrm{a}}$} \\
\hline \multirow[t]{7}{*}{ Intrinsic factors } & Age $>14$ years $^{\mathrm{b}}$ & 4.59 & $1.77-11.90$ & 0.002 \\
\hline & Born first half of year, yes & 2.60 & $1.08-6.27$ & 0.034 \\
\hline & $\mathrm{BMI}>19.9 \mathrm{~kg} / \mathrm{m}^{2 \mathrm{~b}}$ & 2.40 & $0.96-6.00$ & 0.063 \\
\hline & Menarche, yes & 6.68 & $0.90-49.83$ & 0.064 \\
\hline & Previous acute knee injury, yes & 2.05 & $0.60-6.97$ & n.s. \\
\hline & Current knee complaints, yes & 1.02 & $0.37-2.79$ & n.s. \\
\hline & Familial disposition ACL injury, yes & 3.57 & $1.48-8.62$ & 0.005 \\
\hline \multirow[t]{5}{*}{ Extrinsic factors } & Training sessions per week $>1.30^{\mathrm{b}}$ & 0.75 & $0.29-1.93$ & n.s. \\
\hline & Matches per week $>0.72^{b}$ & 0.92 & $0.37-2.26$ & n.s. \\
\hline & Match exposure ratio $>0.26^{\mathrm{b}, \mathrm{c}}$ & 0.79 & 0.33-1.88 & n.s. \\
\hline & Match with other team, yes & 0.61 & $0.22-1.72$ & n.s. \\
\hline & Artificial turf exposure, yes & 0.86 & $0.36-2.06$ & n.s. \\
\hline \multicolumn{5}{|c|}{ Step 2. Multiple analysis ${ }^{\mathrm{a}, \mathrm{d}}$} \\
\hline & Age $>14$ years $^{\mathrm{b}}$ & 2.49 & $0.82-7.51$ & n.s. \\
\hline & Born first half of year, yes & 1.66 & $0.63-4.43$ & n.s. \\
\hline & BMI $>19.9 \mathrm{~kg} / \mathrm{m}^{2 b}$ & 1.56 & 0.61-3.99 & n.s. \\
\hline & Menarche, yes & 3.11 & $0.37-26.45$ & n.s. \\
\hline & Familial disposition ACL injury, yes & 3.82 & $1.56-9.39$ & 0.003 \\
\hline
\end{tabular}

ACL, anterior cruciate ligament; BMI, body mass index; CI, confidence interval.

a All analyses adjusted for group belonging (intervention or control group).

${ }^{\mathrm{b}}$ Variable dichotomised according to below or above cohort mean.

${ }^{c}$ Match hours/total hours of exposure.

${ }^{\mathrm{d}}$ Variables with $P<0.20$ in individual variable analysis were entered into multiple analysis. 
TABLE 5

Sensitivity, specificity, positive and negative predictive values of variables to predict new acute knee injury or ACL injury.

\begin{tabular}{|c|c|c|c|c|c|c|c|c|}
\hline & \multicolumn{4}{|c|}{ Acute knee injury (\%) } & \multicolumn{4}{|c|}{ ACL injury (\%) } \\
\hline & Sensitivity & Specificity & PPV & NPV & Sensitivity & Specificity & PPV & NPV \\
\hline Age $>14$ years & 50 & 67 & 3 & 98 & 71 & 67 & 1 & $>99$ \\
\hline $\mathrm{BMI}>19.9 \mathrm{~kg} / \mathrm{m}^{2}$ & 55 & 56 & 3 & 98 & & & & \\
\hline Menarche & 87 & 26 & 3 & 99 & & & & \\
\hline Previous acute knee injury & 17 & 92 & 4 & 98 & & & & \\
\hline Current knee complaints & 38 & 76 & 3 & 98 & & & & \\
\hline Familial disposition ACL injury & 26 & 85 & 4 & 98 & 38 & 85 & 1 & $>99$ \\
\hline Born first half of year & & & & & 62 & 61 & 1 & $>99$ \\
\hline
\end{tabular}

ACL, Anterior cruciate ligament; BMI, Body mass index; PPV Positive predictive value; NPV Negative predictive value 


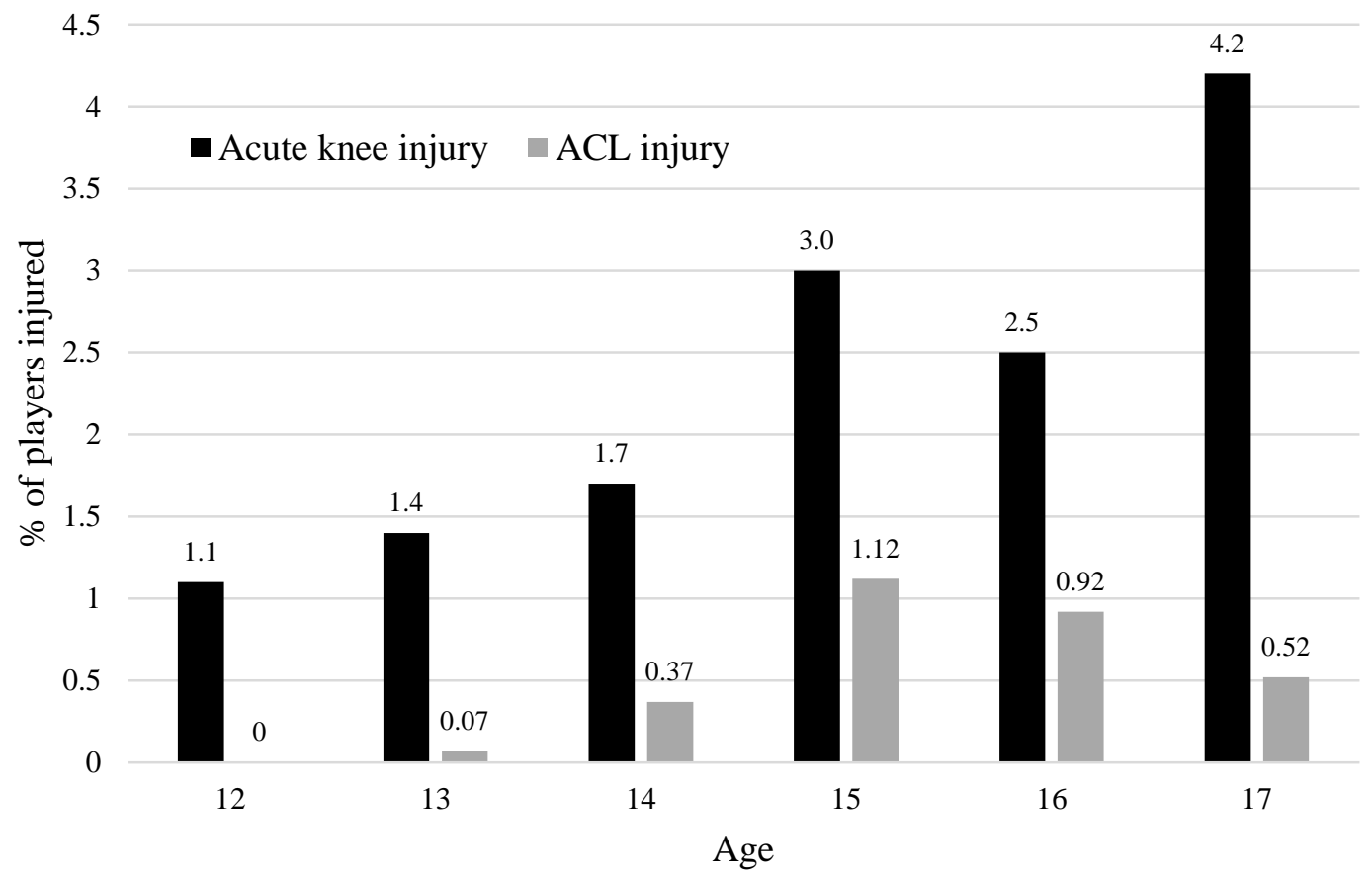

FIGURE 1

Injury proportions by age group 